KEMAS 13 (1) (2017) 69-76
Jurnal Kesehatan Masyarakat

\title{
DIFFERENCES IN RISK FACTOR OF CARDIOVASCULAR DISEASE RISK ON RURAL AND URBAN POPULATION
}

\author{
Cholik Harun Rosjidi ${ }^{\varpi}$, Laily Isro’in, Nurul Sri Wahyuni \\ Faculty of Health Science, Universitas Muhammadiyah Ponorogo, Indonesia
}

\begin{tabular}{l} 
Info Artikel \\
\hline Article History: \\
Submitted October 2015 \\
Accepted July 2017 \\
Published July 2017 \\
\hline Keywords: \\
Cardiovascu- \\
lar; Rural; Urban \\
\hline DOI \\
http://dx.doi.org/10.15294/ \\
kemas.v13i1.4174
\end{tabular}

\section{Info Artike}

Accepted July 2017

kemas.v13i1.4174

\begin{abstract}
Cardiovascular disease is a global threat. This study aimed to obtain a description of cardiovascular disease pattern among rural and urban population in Ponorogo. Two locations were chosen to represent rural and urban area through cluster sampling. Cross sectional study design was chosen with a sample size of 350 respondents. The research instrument was adopted from WHO STEPS. Difference in prevalence between the two clusters were analyzed with $\chi^{2}$ test, with $\alpha=0.05$. The result showed that the prevalence smoking and alcohol consumption among males were higher in rural than urban population ( $\mathrm{p}=0.04$ and $\mathrm{p}=0.012$ respectively). The prevalence of unhealthy fruit consumption was higher in both sexes from rural population $(\mathrm{p}=0.025$ and $\mathrm{p}=0.012)$. Hypertension was higher among rural female compared to female living in urban area $(\mathrm{p}=0.024)$.
\end{abstract}

\section{Introduction}

Non communicable disease (NCD), especially cardiovascular disease, cancer, chronic respiratory disease, and diabetes are major threats for human health and development. The four diseases are the largest killer in the world and $80 \%$ of the cases occur in low and middle income countries. $80 \%$ cases of cardiac disease, stroke, and type 2 diabetes, and also more than a third of cancer can be prevented by eliminating shared risk factors, especially tobacco use, unhealthy diet, and alcohol use (WHO, 2008).

The incidence of NCD in Indonesia is also high. WHO publication (2014), showed that the prevalence of NCD was higher than the combination of infectious, maternal, perinatal, and nutritional diseases. The prevalence of those disease combined were $22 \%$, fewer than chronic (noninfectious) disease such as accident 7\%, cardiovascular disease $37 \%$, chronic respiratory disease $5 \%$, diabetes mellitus $6 \%$, and other NCDs 6\%.

Poor and developing countries showed an increase of cardiovascular disease. High risk for cardiovascular disease has been reported in poor and transitioning countries such as Hong Kong, Puerto Rico, Pakistan, and some countries in Sub-Sahara Africa (Song, 2006; Minh, 2006; Tang, 2003). The main issue is the increasing incidence of cardiovascular diseases in poor countries caused by globalization, urbanization, and increased sedentary lifestyle. Low socioeconomic status worsens the condition, in which people with lower socioeconomic status are more susceptible to

\footnotetext{
Correspondece Address:

Jalan Budi Utomo No 10 Ponorogo, Jawa Timur

Email : cholikharunrosjidi@gmail.com
} 
cardiovascular disease.

Some socioeconomic risk factors related to cardiovascular disease has been identified; they are low education status, occupation, income, race, and gender. The risks of cardiovascular disease are different in male and female. Recent study in Ponorogo showed that females are more susceptible to cardiovascular disease than male. On average, there were 7 risk factors found on male whereas 4 were found on female, this explained that female were more susceptible to cardiovascular disease.

A study conducted in 2012 to obtain the distribution pattern of cardiovascular disease risk on Indonesian workers' family in Ponorogo found that $37.1 \%$ respondents were smokers, $8.2 \%$ consumed alcohol, $69.1 \%$ consumed unhealthy fruit, $99 \%$ consumed healthy vegetables, $30.9 \%$ reported light physical activity, $68 \%$ had hypertension, $28.9 \%$ were overweight, and $38.1 \%$ had risk of diabetes. In 2013, a study to find an association between physical inactivity and obesity was conducted, in which the result showed that the risk of obesity was 9 times higher among respondents with light physical activity compared to respondents with moderate or heavy physical activity (OR=9, 95\% 2,3-35,1). Another study was conducted in 2013 to investigate the susceptibility to cardiovascular disease among female; the result showed that the average number of cardiovascular disease risk factor in female was 5.0 with $\mathrm{SD}=1.9$. The maximum number of risk factor was 9 and minimum number was 0 . The average number of cardiovascular disease risk factor in male was 6.2 with $\mathrm{SD}=1.8$. The maximum number of risk factor was 10 and minimum number was 3. T-test resulted in $p$ value $=0.002$. This proved that there was a significant difference in the number of cardiovascular disease risk factor between male and female. Female was more susceptible to cardiovascular disease than male. These studies' results illustrated that cardiovascular disease has become a serious problem in Ponorogo Regency, which is categorized as a small city.

The issue that must be answered specifically in Indonesia is whether there is any difference in cardiovascular disease risk factor between rich and poor people, urban and rural area, and also female and male. This study is essential to obtain the data about cardiovascular disease pattern between urban and rural area.

\section{Method}

This study used survey method with a cross sectional approach. The sample population was all residents of Ponorogo Regency aged 25 years and older. Sample collection was done in cluster consisting of 175 taken from rural cluster, selected from Siman subdistrict, and 175 samples from urban cluster, selected from the Ponorogo city subdistrict.

This study was conducted in two categories, the rural and urban area in Ponorogo Regency. The study sample was all Ponorogo residents who had time for data collection, consented to participate in the research, and literate. The sample size of this study was 350 . We determined the sample size using two proportion difference formula; from our pilot study we found that the proportion of cardiovascular disease among poor people was $45 \%$ with $\alpha=0,05$ and a precision $15 \%$, hence we obtained the sample size as 85 . Because of the effect cluster sampling, the sample size became 175 for urban area and 175 for rural area. Sample was collected with stratified cluster sampling. First, from 20 districts we chose one subdistrict, then chose one rural village as a cluster sampling unit and from the city subdistrict we selected one urban village; finally, from each rural village and urban village we selected 175 people.

The variables analyzed were dependent and independent variables. The independent variable was respondent's residence. The dependent variables were cardiovascular disease risk factor, consisting of hypertension, diabetes, cholesterol, tobacco smoking, alcohol consumption, diet, and obesity. Operational definition from each variable is presented in table below. Residence status was categorized as urban and rural area. We determined urban and rural area according to map of Ponorogo Regency. Hypertension was respondent's blood pressure which was categorized into hypertension and non-hypertension according to the examination's results. Hypertension was defined as systolic blood pressure $\geq 140$ and diastolic blood pressure $\geq 90$. Diabetes mellitus was the value of patient's blood glucose which 
was obtained from blood glucose measurement and was categorized into diabetes and nondiabetes, according to WHO classification. Cholesterol was blood lipid which was measured from respondent's total cholesterol in the laboratory and was categorized into low and high cholesterol level according to WHO standard. Tobacco consumption of respondent was categorized into smoker and non-smoker. Body Mass Index (BMI) was defined as the ratio between body weight in kilogram and body height in meter square. BMI score was categorized into overweight if $\mathrm{BMI} \geq 26$ and normal if BMI $<26$. Diet of the respondent, which include fruit and vegetables consumption in one week, was categorized as healthy if fruit and vegetables consumption $\geq 5$ times per week. We measured physical activity of respondents using Ipaque scale, divided into heavy-modeate activity and light activity. Age was the current age of the respondents when this study was conducted, expressed in year and classified into $\geq 50$ years and $<50$ years old.

In this study we used primary data that was collected directly from the respondent. We used modified questionnaire from Steps Intruments for NCD Risk Factors WHO as our study instrument. The materials needed were blood glucose meter, body weight scale, sphygmomanometer, and stethoscope. We also used alcohol, alcohol swab with its container, and lancet.

We used univariate analysis to describe each variable's characteristics with a frequency distribution that would be displayed as narration and tables. Characteristic of study subjects were age, education status, occupation, and economy status. We also used bivariate analysis to investigate the association between 2 variables in both groups between dependent and independent variable or dependent and confounding variable. We utilized statistic test to investigate the association between 2 variables using Chi Square ( $\chi 2)$. $2 \times 2$ Table was also used to calculate prevalence ratio with a confidence interval (CI) 95\%. Analysis was done using SPSS software program version 16.0.

\section{Results and Discussions}

The differences in cardiovascular disease risk factor among respondents living in rural area compared to those in urban area according to gender in Ponorogo Regency was as follows: there were a significant difference in tobacco consumption in male $(\mathrm{p}=0.04)$, male who lived in rural area had 2.3 times higher risk to consume tobacco than those living in urban area. Female who lived in rural area also had 3.8 times higher risk those living in urban area, although it was not statistically significant $(\mathrm{OR}=3.8$, CI 95\% 0.8:18.4).

The differences in cardiovascular disease risk factor between respondants living in urban and rural area according to the gender is described in detail in table 2.

The prevalence of tobacco consumption in rural area was $30.9 \%$, whereas in urban area was $26.3 \%$. Tobacco use had been seen as male's habit for a long time. Tobacco consumption was commonly done by male. From our data analysis, there was an association between tobacco consumption and gender. The prevalence of smoking among male in rural area was $78 \%$, whereas in urban area was $62.9 \%$. This study showed that male living in rural area were twice as likely to smoke than those living in urban area $(\mathrm{OR}=2.1,95 \% \mathrm{CI}=1-4.6)$. Although female who lived in rural area were thrice as likely to smoke, it was not statistically significant $(\mathrm{p}=0.75, \mathrm{OR}=3.8,95 \% \mathrm{CI}=0.8-18.4)$.

For many Indonesians, smoking is considered as an ordinary behavior, a part of social live and a lifestyle, without understanding the risk of smoking to their own health and also other people's health. The smoker is not aware that they are trapped in smoking dependence which cannot be easily removed. The rate of dissemination amongst first-timer smoker, specifically on young generation, was high; in some locations some toddlers have even begun smoking.

Although the total cigarette consumption was lower than the national average, $28.6 \%$ was quite high. Cigarette is highly associated to cardiovascular diseases, killing 6 million peoples in developing countries. It increases $\mathrm{COHb}$ concentration by incomplete combustion of organic substances and hence decreasing blood oxygen concentration. Moreover, it could thicken blood vessels wall by increasing fibrinogen concentration. The earlier smoking starts, the faster cardiovascular disease occurs. Chiolero (2008), found that cigarette smoking 
Table 1. Differences in Cardiovascular Disease Risk Factor Between Urban and Rural Area in Ponorogo Regency

\begin{tabular}{|c|c|c|c|c|c|c|}
\hline \multirow{2}{*}{ Variables } & \multicolumn{4}{|c|}{ Residence of Respondent } & \multirow{2}{*}{$\mathrm{X} 2$} & \multirow{2}{*}{$\mathrm{P}$} \\
\hline & Rural & $\%$ & Urban & $\%$ & & \\
\hline \multicolumn{7}{|l|}{ Smoking } \\
\hline Yes & 54 & 30.9 & 46 & 26.3 & 0.89 & 0.344 \\
\hline No & 121 & 69.1 & 129 & 73.7 & & \\
\hline \multicolumn{7}{|c|}{ Alcohol consumption } \\
\hline Yes & 10 & & 5.7 & 2 & 5.52 & $0.02^{*}$ \\
\hline No & 165 & & 94.3 & 173 & & \\
\hline \multicolumn{7}{|l|}{ Fruit consumption } \\
\hline Unhealthy & 81 & 46.3 & 51 & 29.1 & 10.95 & $0.001^{*}$ \\
\hline Healthy & 94 & 53 & 124 & 70.9 & & \\
\hline \multicolumn{7}{|c|}{ Vegetable consumption } \\
\hline Unhealthy & 12 & 6.9 & 14 & 8 & 0.166 & 0.68 \\
\hline Healthy & 163 & 93.1 & 161 & 92 & & \\
\hline \multicolumn{7}{|l|}{ Hypertension } \\
\hline Yes & 93 & 53.1 & 71 & 40.6 & 5.55 & $0.018^{*}$ \\
\hline No & 82 & 46.9 & 104 & 59.4 & & \\
\hline \multicolumn{7}{|l|}{ Central obesity } \\
\hline Yes & 67 & 38.3 & 75 & 42.9 & 0.76 & 0.38 \\
\hline No & 108 & 61.7 & 100 & 57.1 & & \\
\hline \multicolumn{7}{|l|}{ Diabetes mellitus } \\
\hline Yes & 42 & 24 & 54 & 30.9 & 2.07 & 0.15 \\
\hline No & 133 & 76 & 121 & 69.1 & & \\
\hline \multicolumn{7}{|c|}{ Hypercholesterolemia } \\
\hline Yes & 59 & 33.7 & 60 & 34.3 & 0.01 & 0.91 \\
\hline No & 116 & 66.3 & 115 & 65.7 & & \\
\hline \multicolumn{7}{|l|}{ Physical activity } \\
\hline Unhealthy & 129 & 73.7 & 130 & 74.3 & 0.01 & 0.90 \\
\hline Healthy & 46 & 26.3 & 45 & 25.7 & & \\
\hline
\end{tabular}

Source : Primary Data

increase insulin resistance and was related to central fat accumulation.

Generally, $62.3 \%$ respondents consume fruits in the healthy category. The prevalence of fruits and vegetables consumption by urban respondents $(70.9 \%)$ was healthier than respondent in rural area (53.7\%). There was no difference in fruit consumption pattern between men and women in both urban and rural area. The prevalence of unhealthy fruit consumptions in rural area was $50.8 \%$ (men) and $44 \%$ (women), while $31.4 \%$ (men) and $27.6 \%$ (women) in urban area. Both men and women in urban area consumed healthier fruit compared to rural area. Urban men were 2.3 times more likely to consume healthy fruit than rural men $(\mathrm{OR}=2,3,95 \% \mathrm{CI}=1,04-4,94)$, whereas urban women were twice more likely to consume fruits than women living in rural area $(\mathrm{OR}=2,06,95 \% \mathrm{CI}=1,13-3,76)$.

Vegetables consumption pattern was distributed equally among both sexes with a statistically insignificant difference $(p=0,546)$. In the rural area, unhealthy vegetable consumption reached $6.9 \%$ specifically $8.5 \%$ men and 6\% women. Urban respondents 
Table 2 Differences in Cardiovascular Disease Risk Factor Between Respondents Living in Urban and Rural Area According to Gender

\begin{tabular}{|c|c|c|}
\hline $\begin{array}{c}\text { Cardiovascular Disease } \\
\text { Risk Factor }\end{array}$ & $P$ value & OR $(95 \% \mathrm{CI})$ \\
\hline \multicolumn{3}{|l|}{ Smoking } \\
\hline Male & $0.04^{\star}$ & $2.1(0.95: 4.6)$ \\
\hline Female & 0.75 & $3.8(0.8 ; 18.4)$ \\
\hline \multicolumn{3}{|l|}{ Alcohol consumption } \\
\hline Male & $0.012^{*}$ & $6.12(1.3 ; 29.6)$ \\
\hline Female & 0.34 & - \\
\hline \multicolumn{3}{|l|}{ Fruit consumption } \\
\hline Male & $0.025^{\star}$ & $2.26(1.04 ; 4.94)$ \\
\hline Female & $0.012^{\star}$ & $2.06(1.13 ; 3.76)$ \\
\hline \multicolumn{3}{|l|}{ Vegetable consumption } \\
\hline Male & 0.766 & $1.2(0.36 ; 3.99)$ \\
\hline Female & 0.847 & $1.1(0.38 ; 3.28)$ \\
\hline \multicolumn{3}{|l|}{ Physical activity } \\
\hline Male & 0.198 & $1.6(0.73 ; 3.52)$ \\
\hline Female & 0.480 & $1.27(0.62 ; 2.59)$ \\
\hline \multicolumn{3}{|l|}{ Diabetes mellitus } \\
\hline Male & 0.17 & $1.7(0.78 ; 3.82)$ \\
\hline Female & 0.45 & $1.26(0.69 ; 2.27)$ \\
\hline \multicolumn{3}{|l|}{ Hypercholesterolemia } \\
\hline Male & 0.31 & $1.5(0.69 ; 3.07)$ \\
\hline Female & 0.36 & $1.19(0.65 ; 2.15)$ \\
\hline \multicolumn{3}{|l|}{ Hypertension } \\
\hline Male & 0.38 & $1.37(0.64 ; 2.92)$ \\
\hline Female & $0.024^{*}$ & $1.85(1.04 ; 3.27)$ \\
\hline \multicolumn{3}{|l|}{ Obesity } \\
\hline Male & 0.88 & $1.06(0.49 ; 2.30)$ \\
\hline Female & 0.298 & $1.33(0.75 ; 2.35)$ \\
\hline
\end{tabular}

Source : Primary Data

had a more unhealthy diet compared to rural respondents. The prevalence of unhealthy vegetable consumptions in urban area was $8 \%$ specifically $7 \%$ men and $6.7 \%$ women. There was no significant difference in vegetable consumption pattern between men and women in Ponorogo, even though urban respondents had unhealthier vegetable consumption pattern than rural respondents.

Although fruit consumption is important for daily nutrient intake, it is not a habit among rural respondents. Fibers inside fruit and vegetable would dissolve and bind bile acids in which fat is dissolved. Fiber will pass along with feces, meaning that the more vegetable is eaten, the more fat and cholesterol are thrown away, and ultimately reducing fat deposits in the body. In addition, fruits and vegetables consumption reduce the consumption of fat and sugar because fiber give a fullness sensation. Drapeau (2004), stated that increasing fruit and vegetable consumption will reduce body weight and total cholesterol.

When calories consumed is more than calories used in daily activities, the excess calories will be stored as fat deposits. The danger is when fats are stored in the blood vessel wall, causing atherosclerosis, hypertension, type 2 diabetic, obesity which are the risk factors for heart disease and stroke.

This study shows that unhealthy fruits consumption is a major cardiovascular risk factor. Rural respondents consumed less healthy fruits compared to urban respondents; hence 
rural population had higher cardiovascular risk compared to urban population. Based on this study, health promotion regarding healthy fruits consumption needs to focus in rural area with community participation approach.

Ponorogo society had not understood about the criteria of healthy physical activity. This study found no difference in physical activity between urban and rural respondents. Most urban and rural respondents fell under light activity category. The prevalence of unhealthy physical activity in rural area were $73.7 \%$. $42.4 \%$ men had medium to heavy physical activity while $18.1 \%$ women had medium to heavy physical activity. This difference is statistically significant $(p=0,001)$.

Physical activity and sport have many benefits. Regular physical activity can reduce the risk for coronary heart disease, cerebrovascular disease, hypertension, obesity, and osteophorosis (Ignarro , 2007). One of the causes of increased obesity incidence among high income society is the lack of physical activity. Sedentary people should consume lesser calories. People who eat diet rich in fat but lack physical activity tend to be obese. Mustelin (2009), found a relationship between physical activity and waist circumference. Physical activity could modify the effect of one's genetic factor. An increase in physical activity had an apparent relationship with waist circumference.

This research found that most of Ponorogo population had not understood about the criteria of a healthy physical activity. Healthy physical activity should be done three times a week in the medium to heavy activity category. The WHO recommendation for physical activity to reduce cardiovascular disease is at least 30 minutes of medium physical activity done routinely. American Heart Association also recommended 30 minutes medium to heavy aerobic activity daily to improve the health of heart, lung, and circulation. The term physical activity is not merely about sport but also can be daily activity i.e. walking to the market, sweeping the house, washing clothes, and moping. Body movement can burn the body fat store.

Based on the result of this study, it is important to create a program to encourage physical activity among Ponorogo populations and engage all sectors (healthcare professionals, public health office, education, industry, etc.) involved in the prevention of cardiovascular disease.

Hypertension is major cause of cardiovascular disease. Hypertension is diagnosed based on the individual's blood pressure. Blood pressure is a force applied to the blood vessel wall. This pressure varies with the blood vessel condition and heart rate.

This research found that the prevalence of hypercholesterolemia was about $34 \%$. That prevalence in rural area was $33.7 \%$ while in urban area was $34.3 \%$. Compared to men, women in both urban and rural areas had higher prevalence of hypercholesterolemia. The prevalence of hypercholesterolemia was $36.2 \%$ in women and $28.8 \%$ in men living in rural area. Moreover, in urban area, hypercholesterolemia occurs in $56.7 \%$ women and $43.4 \%$ men. Although there was no significant difference between urban and rural population in Ponorogo, the data showed that the prevalence of hypercholesterolemia was higher among urban population compared to rural population.

Body fat fraction includes total cholesterol, LDL, HDL, and triglyceride. Cholesterol is essential for human body which functions as material for sex hormone synthesis, cell wall component, etc. Both fat and cholesterol become dangerous when their level is abnormally high. Hypercholesterolemia is a common problem in modern society and it is a reflection of the daily high fat intake. Cholesterol is connected to coronary heart disease. The risk of coronary heart disease is higher if hypercholesterolemia is present together with other risk factor i.e hypertension and cigarette smoking. The increase of total cholesterol and low-density lipoprotein (LDL) in serum are important cardiovascular risk factor for both men and women. Masriadi, (2016) found that dyslipidemia is the main risk factor for the development of coronary heart disease in women aged more than 45 years old.

This study showed a serious problem in Ponorogo population, especially the urban population where the prevalence of hypercholesterolemia was high. The prevalence of hypercholesterolemia was higher among 
women than men, both in rural and urban areas. Therefore, health promotion on the effect of hypercholesterolemia must be increased, especially in the urban area and women as the main target.

Obesity is the result of imbalance between dietary intake and physical activity, i.e someone who eat fat and protein more than his/her physical activity. This results is corresponding with Erem (2004) that there was a relationship between physical activity and obesity. Overweight increases cardiovascular disease risk in various ways. This is consistent with Korneliani, K and Meida, D (2012) in which obese subjects had 3.8 times higher risk for developing hypertension. Another study by Kamso (2011), found that obesity is a risk for metabolic syndrome. The higher the weight, the more blood volume is needed to supply oxygen across the body and in turn gives greater pressure to the arterial wall. Throughout the world, people nowadays consume more high energy food, high glucose, high fat and salty food. In poor countries, nutrition pattern and physical activity change rapidly compared to rich countries, hence chronic disease incidence are increasing rapidly in several poor countries. The latest data showed that the incidence of obesity increases globally, including in Indonesia.

This study found that obesity was more common among urban population compared to than rural population. In addition, it was more prevalent among women compared to men in both urban and rural areas. Obesity was an important problem in Ponorogo and a solution is needed to solve the problem.

Diabetes mellitus is defined as random blood glucose equal to or greater than $200 \mathrm{mg} /$ $\mathrm{dL}$. This criteria is only a presumption diagnosis because this measurement has many weaknesses. This study found diabetes mellitus in $27.4 \%$ respondents, which is higher than national average of $6 \%$.

Diabetes mellitus is frequently called as the great initiator, meaning it attacks all organs with various symptoms. The symptoms varies widely and frequently progresses slowly and unnoticed by the patient. The clinical appearance is often unclear or sometimes asymptomatic and is commonly found when the patient undergoes examination for other medical conditions. The complications of diabetes include microangiopathy i.e thickening of blood vessel wall in the eyes, kidney, brain, and heart. The complications/organ damage occur slowly and unnoticed by the patient, leading to a delay in diagnosis, and often diagnosed after complications have arisen.

This study also found that diabetes was more prevalent among men living in urban areas compared to women, conversely in rural area diabetes was more prevalent among women compared to men. DM risk factor detection is very important while paying attention to the territory in order to map the cause and risk factor clearly.

A cardiovascular disease prevention and management program based on scientific evidence is needed to create an effective and efficient program. This study provides scientific evidence as the basis to create the program in Ponorogo. Synergism of various stakeholder and cross-sectoral teamwork is needed to manage cardiovascular diseases. The result of this study can be used as an evidence or advocacy material to develop public policy on cardiovascular disease prevention.

\section{Conclution}

Cigarette smoking, alcohol consumption, unhealthy fruits consumption, and hypertension are cardiovascular disease risk factors that are more prevalent in rural area compared to urban area. Meanwhile, unhealthy vegetables consumption, obesity, $\mathrm{DM}$, and hypercholesterolemia are risk factors that are more prevalent in urban area. Hypertension, hypercholesterolemia, obesity, physical inactivity, and DM are cardiovascular risk factors which is more prevalent among women. The creation of cardiovascular disease management programs should involve various stakeholders and use the healthy partnership principle.

\section{References}

Chiolero, A. Faeh, D. Paccaud, F. \& Jacques, C. 2008. Consequences of smoking for body weight, body fat distribution, and insulin resistance. Am J Clin Nutr; 87:801-9

Drapeau, V. et al. 2004. Modifications in food-group consumption are related to long-term bodyweight changes. Am. J. Clin Nutr, 80:29-37

Erem, et al . 2012. Prevalence of Obesity and 
Associated Risk Factors in a Turkish Population (Trabzon City, Turkey). Obesity Research, 12: 1117-1128

Ignarro, L.; Balestrieri,L. \&Napoli, C.2007.Nutrition, physical activity, and cardiovascular disease: An update. Elsevier, 73 (10): 326-40.

Kamso, S. et al. 2011. Prevalensi dan Determinan Sindrom metabolik pada Kelompok Eksekutif di Jakarta dan Sekitarnya. Jurnal Kesmas, 6(2): 85-90.

Korneliani, Kiki \& Meida Dida. 2012. Hubungan Obesitas dan Stress dengan kejadian Hipertensi Guru SD Wanita. Jurnal Kemas, 7 (2): 111-115

Masriadi, Hasta Handayani Idrus \&, Arman. 2016. Faktor Risiko Penyakit Jantung Koroner pada Perempuan Usia Lebih dari 45 Tahun di Makassar. Kesmas: National Public Health Journal.; 11 (2): 79-85

Minh, H. V.; et al. 2006 Cardiovascular Disease Mortality and Its Association With Socioeconomic Status: Findings From a Population-based Cohort Study in Rural Vietnam, 1999-2003. Preventing Chronic Disease. Public Health Research, Practice, and Policy, 3: no 3
Mustelin L, et al . 2009. Physical Activity Reduces the Influence of Genetic Effects on BMI and Waist Circumference: a study in young adult twins, ; 33(1):29-36

Song Y.M. et al. 2006. Socioeconomic Status and Cardiovascular Disease Among Men: The Korean National Health Service Prospective Cohort Study. American Journal of Public Health . 96: 152-159.

Tang, M. Chen, Y. Krewski, D. 2003. Genderrelated differences in the Association between Socioeconomic Status and Selfreported Diabetes. International Journal of Epidemiology, 32: 381-385

World Health Organization. 2008. 2008-2013 Action Plan for the Global Strategy for the Prevention and Control of Noncommunicable Diseases: Prevent and Control Cardiovascular Diseases, Cancers, Chronic Respiratory Diseases and Diabetes. Geneva, the WHO Document

World Health Organization. 2014. Noncommunicable Diseases Country Profiles 2014. Geneva, Printed by the WHO Document Production Services. 